\title{
Comparison of the optical depth of total ozone and atmospheric aerosols in Poprad-Gánovce, Slovakia
}

\section{Peter Hrabčák}

Slovak Hydrometeorological Institute, Poprad-Gánovce, 058 01, Slovakia

Correspondence: Peter Hrabčák (peter.hrabcak@shmu.sk)

Received: 28 March 2017 - Discussion started: 10 May 2017

Revised: 13 April 2018 - Accepted: 30 April 2018 - Published: 1 June 2018

\begin{abstract}
The amount of ultraviolet solar radiation reaching the Earth's surface is significantly affected by atmospheric ozone along with aerosols. The present paper is focused on a comparison of the total ozone and atmospheric aerosol optical depth in the area of Poprad-Gánovce, which is situated at the altitude of $706 \mathrm{~m}$ a.s.l. in the vicinity of the highest mountain in the Carpathian mountains. The direct solar ultraviolet radiation has been measured here continuously since August 1993 using a Brewer MKIV ozone spectrophotometer. These measurements have been used to calculate the total amount of atmospheric ozone and, subsequently, its optical depth. They have also been used to determine the atmospheric aerosol optical depth (AOD) using the Langley plot method. Results obtained by this method were verified by means of comparison with a method that is part of the Brewer operating software, as well as with measurements made by a Cimel sun photometer. Diffuse radiation, the stray-light effect and polarization corrections were applied to calculate the AOD using the Langley plot method. In this paper, two factors that substantially attenuate the flow of direct ultraviolet solar radiation to the Earth's surface are compared. The paper presents results for 23 years of measurements, namely from 1994 to 2016. Values of optical depth were determined for the wavelengths of 306.3, 310, 313.5, 316.8 and $320 \mathrm{~nm}$. A statistically significant decrease in the total optical depth of the atmosphere was observed with all examined wavelengths. Its root cause is the statistically significant decline in the optical depth of aerosols.
\end{abstract}

\section{Introduction}

It is known that anthropogenic changes in the amount of total ozone and atmospheric aerosols have a considerable impact on the solar UV radiation reaching the Earth's surface (De Bock et al., 2014; Czerwińska et al., 2016). An increased transmittance of UV radiation through Earth's atmosphere has a manifested influence on human health and natural ecosystems. Higher doses of UV radiation have adverse effects mainly on terrestrial plants that are exposed to it on a long-term basis (Jansen et al., 1998). Exposure of human organisms to excessive UV radiation doses may cause premature ageing of the skin, weakening of the immune system and damage to cells and DNA, which may even consequently lead to skin cancer and other diseases (Greinert et al., 2015). Positive effects of UV radiation are known as well, which include vitamin D production in the skin in particular. This vitamin is much needed for proper functioning of a human organism (Kimlin and Schallhorn, 2004). In the past, the anthropogenic impact led to an increased transmittance of solar UV radiation through Earth's atmosphere as a result of a decrease in the total amount of ozone. Global ozone layer depletion began to show more significantly in the 1980 s, reaching its peak with the value of ca. $5 \%$ (with respect to the average for the period of 1964-1980) in the early 1990s. The depletion has already been reduced in recent years, amounting to ca. $3 \%$ on average for the whole Earth (WMO, 2014). In the middle latitudes of the Northern Hemisphere $\left(35-60^{\circ} \mathrm{N}\right)$, the depletion of the ozone layer reached $3.5 \%$ around 2010 (2008-2012). Depletion of up to $6 \%$ was found in the middle latitudes of the Southern Hemisphere $\left(35-60^{\circ} \mathrm{S}\right)$ in the same period (WMO, 2014).

On the other hand, anthropogenic emission of aerosols into the atmosphere causes a reduction of solar UV radia- 
tion reaching the Earth's surface, especially in industrialized areas. In the early 1990s, it was determined that solar UV$B$ radiation had decreased by ca. $5-18 \%$ in non-urbanized areas of industrialized countries since the Industrial Revolution as a result of air pollution (Liu et al., 1991). Anthropogenic aerosols may reduce the UV radiation reaching the Earth's surface by more than $50 \%$ even in highly polluted urban areas (Krotkov et al., 1998; Sellitto et al., 2006). Anthropogenic emissions of aerosols have been gradually reduced in the developed countries, and a drop in the aerosol optical depth (AOD) has been observed in several locations (Kazadzis et al., 2007; Mishchenko and Geogdzhayev, 2007; Alpert et al., 2012; de Meij et al., 2012; Zerefos et al., 2012). Aerosols have a substantial effect on other physical and chemical processes taking place in the atmosphere as well (Seinfeld and Pandis, 2006; Raghavendra Kumar et al., 2010). They predominantly affect the chemical composition of the troposphere and, in certain cases, of the stratosphere, primarily with regard to major solar eruptions or aircraft flights (Finlayson and Pitts, 2000; Seinfeld and Pandis, 2006). They can reduce the visibility (Lyamani et al., 2010) and also have a significant effect on human health in many cases (WHO, 2006). The presence of aerosols in the atmosphere has an impact on the energy balance of the Earth as well, namely directly, semi-directly and indirectly (De Bock et al., 2010). Finally, the anthropogenically emitted aerosol particles considerably contribute to the ongoing global climate change, while their influence on the radiation balance is still uncertain to a great extent (IPCC, 2014, and references therein).

This paper is focused primarily on the aerosol optical depth obtained by measurements made using the Brewer ozone spectrophotometer and presents one of the possible methodical approaches to its calculation. The presented method is verified by means of an alternative method of AOD calculation and is also verified by Cimel sun photometer measurements. In the paper, obtained values of AOD are compared with the impact of total atmospheric ozone optical depth on the reduction of solar UV radiation. The Brewer spectrophotometer allows for determining the optical depth in the UV region of the spectrum for the wavelengths of $306.3,310,313.5,316.8$ and $320 \mathrm{~nm}$. It was determined for the period of 1994-2016. The examined series is 23 years long, which enabled us to quantify a linear trend of examined optical depth characteristics.

The employment of Brewer spectrophotometer measurements to determine the AOD has already been published in many studies. Some of them presented only short series of measurements. Therefore, they do not include multiannual trends of AOD (Carvalho and Henriques, 2000; Kirchhoff et al., 2001; Marenco et al., 2002). It is mainly more recent papers that also present multiannual measurements, but they do not always present trend information. It is stated in Jarosławski et al. (2003) that the development of AOD for the Polish Belsk station in the period of 1992-2002 appears to have no trend. A quantification of the trend for the Belgian Uccle station can be found in Cheymol and De Backer (2003). It indicates a significant negative trend at the level of $2 \sigma$ for all wavelengths for Brewer MKII spectrophotometer measurements in the period of 1989-2002. For example, the trend value for $320.1 \mathrm{~nm}$ is $-2.13 \pm 0.39 \%$ year $^{-1}$. It also states that an equally significantly negative trend was not observed for the period of 1984-2002. The trend value for the same wavelength was only $-0.78 \pm 0.42 \%$ year $^{-1}$ in that period. The trend is also mentioned in Kazadzis et al. (2007), namely for the Greek Thessaloniki station in the period of 1997-2005. Data analysis for the Brewer MKIII spectrophotometer adjusted for the seasonal cycle using a linear regression showed the trend of $-2.9 \pm 0.92 \%$ year $^{-1}$ for the wavelength of $320.1 \mathrm{~nm}$. It was also determined by a Student's $t$ test that the statistical significance of this change was more than $99 \%$.

\section{Methodology}

\subsection{Location of experiment}

The Brewer ozone spectrophotometer (MKIV) and the Cimel sun photometer are located on the roof of a building of the Aerological and Radiation Centre, Slovak Hydrometeorological Institute (SHMI), in Gánovce near the city of Poprad. Its coordinates are $49.03^{\circ} \mathrm{N}, 20.32^{\circ} \mathrm{E}$ with an altitude of $706 \mathrm{~m}$ a.s.l. The aerosol content in the air, both total amount and composition by types, is determined by local sources on the one hand and by atmospheric circulation on the other hand, which can move a certain air mass together with aerosols even for several thousand kilometres. In isolated instances, it may also transport Saharan dust from Africa. The Saharan dust was present over the Slovak Republic for at least 20 days in 2016 (Hrabčák, 2016). Major local sources include products of solid fuel combustion in adjacent municipalities and agriculture. A bare dry soil or even plant products are often blown away by wind, as the location is rather windy. The proximity of the city of Poprad (ca. $1.5 \mathrm{~km}$ ) with population of ca. 53000 and various industrial activities plays a certain role as well. On the other hand, it is a submontane location, since the highest mountain of the Carpathian mountains ( $2655 \mathrm{ma}$ a.s.l.) is situated only $20 \mathrm{~km}$ away from the station. In spite of the proximity of the mentioned city, the area can, in general, be deemed rural with respect to the anthropogenic impact.

\subsection{Instrumentation}

The Brewer ozone spectrophotometer (No. 97, a single monochromator, model MKIV) is a scientific instrument operating in the ultraviolet and visible region of the solar spectrum. The Brewer spectrophotometer was originally designed to measure the vertical column of ozone in the atmosphere (Brewer, 1973). Moreover, the model MKIV allows 
for measuring the vertical column of $\mathrm{SO}_{2}, \mathrm{NO}_{2}$ (for this purpose, measurements of solar radiation are made in the visible region of the spectrum) and global UV radiation (from 290 to $325 \mathrm{~nm}$, with an increment of $0.5 \mathrm{~nm}$ ). The instrument analyses the solar radiation reaching the Earth's surface using its optical system and selects predetermined wavelengths with higher and lower absorption of $\mathrm{O}_{3}$ and $\mathrm{SO}_{2}$ from the ultraviolet part of its spectrum. On the basis of different radiation absorption for the selected wavelengths, it is possible to derive the total amount of given gases in the vertical column of the atmosphere. More information about the instrument and the measurement procedure can be found in Kerr (2010).

The Brewer spectrophotometer performs standard measurements of direct solar radiation (DS) in the UV region at five selected wavelengths, namely $306.3,310,313.5,316.8$ and $320 \mathrm{~nm}$. They are not completely identical for individual instruments, which is given by minor differences in the position of a measurement slit and other minute mechanical and optical differences (Savastiouk and McElroy, 2005). The aforementioned five wavelengths represent their long-term average, as very small changes in their size occur over the years. The instrument No. 097 has undergone regular 2-year calibrations and daily tests using internal lamps (mercury and standard lamp) from the start of the measurements (18 August 1993). The calibrations are provided by the International Ozone Services (IOS). The instrument is calibrated against the World Brewer reference triad (World Meteorological Organization standards), maintained by Environment Canada, by means of a portable reference instrument No. 017 .

Direct solar radiation measurements can be used to determine the AOD as well. This optical property can be determined in the ultraviolet region of the solar spectrum for the five aforementioned wavelengths, for which the DS measurement is performed by default. It is known that the utilization of the Brewer spectrophotometer to calculate the AOD encompasses particular sources of potential systematic errors. If these errors are neglected, it may lead to negative values of the Ångström exponent for the examined wavelengths (Arola and Koskela, 2004). The first source of errors is the impact of the undesired diffuse radiation contribution to the DS measurements. The second source is the daily cycle of ozone in urbanized areas. The third source is neglecting of the $\mathrm{NO}_{2}$ absorption. In addition, the spectral stray-light effect is the fourth source for the single monochromator. It is stated in Arola and Koskela (2004) that neglecting the diffuse radiation is potentially the biggest source of errors. On the contrary, the stray-light effect has the lowest impact. Unlike the AOD for the shortest and the longest wavelengths, its impact in the cited paper is approximately 7 fold lower than the diffuse radiation impact. In the light of the listed errors, it is not recommended to determine extraterrestrial constants (ETCs) using the Langley plot method (LPM) for low altitude stations in urbanized areas, unless corrections for the impact of diffuse radiation and the daily cycle of ozone are known. Poprad-Gánovce is not a typical station in a low-altitude ur- banized area and is not even a typical high mountain station. It is between these two cases.

The impact of the daily ozone cycle and $\mathrm{NO}_{2}$ can be neglected considering the rural location and higher altitude of the Poprad-Gánovce station. The diffuse radiation impact and stray-light effect were not neglected. Therefore, a recommendation to ensure the air-mass factor does not exceed the value of 3 in the calculation of ETCs was taken into account (Arola and Koskela, 2004; De Bock et al., 2010). It is important to mention that the internal polarization effect is another potential source of systematic errors as well (Cede et al., 2006). It occurs due to the combined effect of two polarization-sensitive elements of the Brewer spectrophotometer: the entrance window is the first and the grating is the second. The polarization effect depends on the zenith angle of the Sun and is almost wavelength independent. The polarization effect for the instrument No. 97 was not determined directly. It is assumed that the dependence of the polarization effect on the zenith angle is similar for all types of Brewer spectrophotometers (Cede et al., 2006). As a result, corrections (the field measurements method) published in Cede et al. (2006) could be applied to the instrument No. 97. The impact of temperature changes was considered. The corrections resulting from the changes in temperature of the instrument are allowed for in the adjustment of raw data.

The CE $318 \mathrm{NE} \mathrm{dP}$ automatic Cimel sun photometer was used to verify the AOD values obtained by the Brewer spectrophotometer. It is an instrument that enables us to measure the direct, diffuse and polarized solar radiation. It performs measurements of direct solar radiation for the selected wavelengths in the ultraviolet, visible and infrared region of the spectrum (Cimel Electronique, 2015). AOD values obtained for the wavelengths of 340 and $380 \mathrm{~nm}$ were used for comparison with the measurements of the Brewer spectrophotometer. The Cimel sun photometer began to perform first measurements at the Poprad-Gánovce station on 12 December 2014. If the conditions allow, it is in automatic operation every day except for the calibration period. For that reason, no continuous measurements are available. The calibration period is approximately 2 months long, and the instrument is away from the station during that time. The calibration is provided within the AERONET (AErosol RObotic NETwork) global network and is carried out by Service National d'Observation PHOTONS/AERONET, Laboratoire d'Optique Atmosphérique, CNRS-Université de Lille. Only the level 2.0 data were used in this paper. It is the highest possible level defined within AERONET.

\subsection{Calculation of total ozone optical depth}

Measured values for the total column ozone amount (TCO) obtained by the DS procedure were used to calculate the total ozone optical depth. A DS measurement is accepted only for an air-mass factor of the ozone layer of less than 4 (as recom- 
mended by IOS) and it takes approximately $2.5 \mathrm{~min}$. During that time, the density of solar radiation flow is measured five times for each of the five wavelengths. Thus five values of total ozone in Dobson units (DU) are obtained from a single DS measurement, which are consequently used to calculate an average and a standard deviation (SD). Only the measurements that meet the SD criterion $(\mathrm{STDEV} \leq 2.5 \mathrm{DU})$ are selected for further data analysis. The total ozone was calculated using the Brewer spectrophotometer B data files analysis programme v. 5.0 (O3Brewer) by Martin Stanek (http: //www.o3soft.eu/o3brewer.html, last access: May 2018). The optical depth was calculated for each accepted value of the total ozone. The calculation is represented by the following equation:

$\tau_{\lambda, \mathrm{O}_{3}}=\Omega_{\mathrm{O}_{3}} \alpha(\lambda, T)=\Omega_{\mathrm{O}_{3}} \sigma(\lambda, T) n$,

where $\tau_{\lambda, \mathrm{O}_{3}}$ is the total ozone optical depth, $\Omega_{\mathrm{O}_{3}}$ is the total ozone in Dobson units, $\alpha(\lambda, T)$ is the absorption coefficient for ozone, $\sigma(\lambda, T)$ is the effective absorption cross section of the ozone molecule (it is usually quantified for $1 \mathrm{~cm}^{2}$ ) and $n$ is the molecule count in the volume determined by $1 \mathrm{DU}$ and $1 \mathrm{~cm}^{2}$; for $\mathrm{O}_{3}$, it is a constant with the value of $n=2.687 \times 10^{16} \mathrm{~cm}^{-3}$ (Schwartz and Warneck, 1995). It is recommended in Carlund et al. (2017) to utilize the same effective absorption cross sections of the ozone molecule to calculate both the TCO and its optical depth, which is required to determine the AOD. The Brewer operating software for the Brewer spectrophotometer utilizes the effective absorption cross sections of the ozone molecule, which are determined on the basis of Bass and Paur measurements (Bass and Paur, 1985). This scale is employed to calculate the total amount of ozone within the network of Brewer spectrophotometers according to the recommendations of the International Ozone Commission (http://www. esrl.noaa.gov/gmd/ozwv/dobson/papers/coeffs.html, last access: June 2017). Today, more recent and accurate values of effective absorption cross sections are already available based on measurements from the Molecular Spectroscopy Lab, Institute of Environmental Physics (IUP), University of Bremen, (http://www.iup.physik.uni-bremen.de/gruppen/ molspec/databases/index.html, last access: May 2018); Gorshelev et al., 2014; Serdyuchenko et al., 2014).

More recent values according to the IUP were used to calculate the ozone optical depth and the AOD. In order to preserve the consistency between the calculation of optical depth and the calculation of the TCO, it was necessary to calculate the TCO values according to a more recent set from the IUP. This calculation was carried out as per the recommendations in Redondas et al. (2014). The dependence of effective cross section on temperature is very important. A so-called effective temperature for the given gas is usually used. In the case of ozone measurements using the Brewer spectrophotometer, an average standard effective temperature of $-45^{\circ} \mathrm{C}(228.15 \mathrm{~K})$ is defined (Redondas et al., 2014). Another difference in the calculation of the TCO compared to the Brewer operating software pertained to the used absorption coefficients for Rayleigh scattering. Instead of coefficients used by default, the value of TCO was determined with coefficients according to Bodhaine et al. (1999), which is in line with coefficients used to calculate the optical depth. Brewer operating software and O3Brewer software use the same formula to calculate an air-mass factor for ozone. The same applies to Rayleigh scattering. The given formulas are defined in the Brewer MKIV Spectrophotometer Operator's Manual (SCI-TEC Instruments Inc., 1999). Different, yet on the other hand more accurate formulas, were used to calculate the AOD by the LPM - for ozone according to Komhyr (1980) and for Rayleigh scattering according to Kasten and Young (1989).

\subsection{Calculation of aerosol optical depth}

The LPM was employed to calculate the AOD. It is a traditional method employed to calculate the AOD by the Brewer spectrophotometer (Carvalho and Henriques, 2000; Kirchhoff et al., 2001; Silva and Kirchhoff, 2004; Cheymol et al., 2006; Sellitto et al., 2006). This method requires stable atmospheric conditions in order to determine the ETC. It needs mainly low variability in the total ozone and atmospheric aerosols during the period of measurements. It is also necessary to avoid any impact of cloudiness on direct solar radiation (DS) measurements and to ensure a sufficient range of zenith angles of individual DS measurements during the day, which is needed for the given method.

For the said reasons, this method is most appropriate for lower latitudes (especially in mountainous regions near the tropics), and it has certain limitations in the middle and particularly higher latitudes (Nieke et al., 1999; Marenco, 2007). This method of AOD calculation has already been applied to the examined location of Poprad-Gánovce in the past (Pribullová, 2002). An alternative method of AOD calculation, implemented by Vladimir Savastiouk, has been available since 2005 (Savastiouk and McElroy, 2005; Savastiouk, 2006; Kumharn et al., 2012). In this case, an algorithm of AOD calculation is part of the Brewer operating software. Hence, the given method will be referred to as the Brewer software method (BSM) in this paper. The fundamental difference against the previous method is that ETCs for individual wavelengths are not determined using the LPM. They are obtained during the calibration of the instrument, hence once in 2 years. Their values are determined during the calibration based on a comparison with the portable reference Brewer instrument No. 017. ETCs for the reference instrument are determined by LPM at the Mauna Loa or Izañ a observatory. Neglected changes in the sensitivity of the instrument over shorter time periods represent a disadvantage of both methods, as the ETCs are fixed for a longer period, 2 years in both cases. The LPM applied in this paper employs fixed ETCs for a 2-year intercalibration period, which is identical with the standard intercalibration period for the measurement 
of ozone. It is assumed that any significant service modifications to the Brewer spectrophotometer during calibration may affect both the calculation of ozone and the calculation of AOD. For that reason, a period not exceeding 2 years was used.

To calculate the AOD, it was necessary to apply the BeerBouguer-Lambert law:

$$
\begin{aligned}
S_{\lambda} & =S_{0, \lambda} \mathrm{e}^{-\mu_{\mathrm{w}} \tau_{\lambda}}=S_{0, \lambda} \mathrm{e}^{-\mu_{\mathrm{O}_{3}} \tau_{\lambda, \mathrm{O}_{3}}-\mu_{\mathrm{r}} \tau_{\lambda, \mathrm{r}}-\mu_{\mathrm{a}} \tau_{\lambda, \mathrm{a}}} \\
& =S_{0, \lambda} \mathrm{e}^{-\mu_{\mathrm{O}_{3}} \alpha(\lambda, T) \Omega_{\mathrm{O}_{3}}-\mu_{\mathrm{r}} \frac{\beta(\lambda) P}{P_{\mathrm{std}}}-\mu_{\mathrm{a}} \tau_{\lambda, \mathrm{a}}},
\end{aligned}
$$

where $S_{\lambda}$ is the flux density of solar radiation flow for the selected wavelength expressed by photon count per unit of time on Earth's surface, $S_{0, \lambda}$ is the flux density of solar radiation flow for the selected wavelength expressed by photon count per unit of time above Earth's atmosphere (extraterrestrial constant - ETC), $\tau_{\lambda}$ is the total optical depth of atmosphere, $\tau_{\lambda, \mathrm{O}_{3}}$ is the optical depth for ozone, $\tau_{\lambda, \mathrm{r}}$ is the optical depth for Rayleigh scattering, $\tau_{\lambda, \mathrm{a}}$ is the optical depth for aerosols, and $\mu_{\mathrm{w}}$ is the air-mass factor for atmosphere as a whole. Its value was calculated as a weighted arithmetic average of individual aforementioned components, while the optical depth of a given component was the weighting factor.

Furthermore, $\mu_{\mathrm{O}_{3}}$ is the air-mass factor of the ozone layer determined according to Komhyr (1980), $\mu_{\mathrm{r}}$ is the airmass factor for Rayleigh scattering determined according to Kasten and Young (1989), $\mu_{\mathrm{a}}$ is the air-mass factor of aerosols $\left(\mu_{\mathrm{a}}<4\right.$ for AOD), while due to the similar vertical profile of aerosols and water vapour it holds that $\mu_{\mathrm{a}} \cong \mu_{\mathrm{H}_{2} \mathrm{O}}$, where $\mu_{\mathrm{H}_{2} \mathrm{O}}$ is the air-mass factor of water vapour determined according to Kasten (1966). Next element $\alpha(\lambda, T)$ is the absorption coefficient for ozone, $\Omega_{\mathrm{O}_{3}}$ is the total amount of ozone in Dobson units, $\beta(\lambda)$ is the normalized optical depth for Rayleigh scattering (for the standard atmospheric air pressure and the vertical column), $P$ is the atmospheric air pressure in the location of observation (the daily average was used), and $P_{\text {std }}$ is the standard atmospheric air pressure $(101325 \mathrm{~Pa})$. The contribution of sulfur dioxide was neglected, mainly due to its low impact (Arola and Koskela, 2004) and due to its inaccurate determination at the PopradGánovce station as well.

The normalized optical depth for Rayleigh scattering $\beta(\lambda)$ was calculated according to Bodhaine et al. (1999). The use of coefficients according to Bodhaine et al. (1999) is in compliance with the recommendations of NOAA (National Oceanic and Atmospheric Administration). A NOAA document (https://www.esrl.noaa.gov/gmd/grad/neubrew/docs/ RayleighInBrewer.pdf) states that standard coefficients for the Brewer operating software must not be used to calculate the AOD. It is stated in Carlund et al. (2017) that the total amount of ozone calculated using the standard coefficients is higher compared to the use of coefficients according to Bodhaine et al. (1999).

The value of $S_{\lambda}$ was obtained by adjustment of raw data (raw counts). It is essential to keep the sequence of the following steps in their adjustment. In the first step, raw counts saved in a B-file were converted to count rates. In the second step, dead time compensation was applied. After the dead time compensation, a correction was applied to the stray-light effect in the same manner as in Garane et al. (2006). In the fourth step, a correction for the temperature dependence was applied, including a spectral transmittance correction for the utilized neutral density (ND) filter. These filters are automatically selected by the Brewer spectrophotometer with respect to the current density of the solar radiation flow. There are 5 ND filters and 5 wavelengths as well, so 25 attenuation values are needed in total. The attenuation values of given filters are determined during the calibration of the instrument. The impact of polarization was compensated for in the fifth step. The sixth and last step involved the correction due to the impact of diffuse radiation on DS measurements. When the above criteria are applied, five initial values of $S_{\lambda}$ will be obtained from a single DS measurement, and subsequently, the AOD will be calculated from each of them. The final AOD for the given DS measurement is calculated as an arithmetic average of five values.

\subsubsection{Correction for the diffuse radiation and stray-light effect}

The correction of the diffuse radiation impact on DS measurements was made following the recommendations in Arola and Koskela (2004). The fact that the full field of view reached the value of 2.6 for the Brewer spectrophotometer was taken into consideration. A ratio of the circumsolar radiation to the direct solar radiation was calculated using the SMARTS 2.9.5 programme (available at https://www.nrel. gov/rredc/smarts/). The calculations in SMARTS were implemented for rural aerosol conditions, which are characterized by an Ångström exponent equal to 0.96 . The ratio of the circumsolar radiation to the direct solar radiation was determined for all five wavelengths. This ratio is hereinafter referred to as the correction factor. The values of zenith angle, aerosol optical depth and atmospheric air pressure were taken into account in the calculation of the correction factor. It follows that this factor was determined for specific conditions at a given time.

Another undesired phenomenon is the influence of noise photons (received outside the range of the analysed wavelength) on the photon detector. The noise photons are caused by radiation that does not follow the required optical path inside the monochromator due to scattering on the grating, mirror or housing. This problem is called the straylight effect and is negligible for the double monochromators. The Brewer spectrophotometer at the Poprad-Gánovce station is a single monochromator. For that reason, a correction for the stray-light effect was necessary (Arola and Koskela, 2004; Garane et al., 2006). The correction was determined by analysing the spectral global UV radiation measured on cloudless days. It was feasible because the optical light path 
is the same for both the UV and DS measurement in the monochromator. The potential impact of a different measurement mode was neglected for the sake of simplification. In general, it is assumed that at the lowest wavelengths, i.e. below $292 \mathrm{~nm}$, there is no transmittance of radiation to the Earth's surface due to absorption in the atmosphere, and any signal measured must, therefore, be stray light. In view of simplification, it is also assumed that the value of stray light is constant for all wavelengths. The said simplifications may lead to some uncertainties when estimating the stray light effect. These uncertainties were not investigated further.

\subsubsection{Calculation of extraterrestrial constants}

The ETC $S_{0, \lambda}$ was determined using the LPM. The LPM employs multiple measurements of the direct solar radiation at various zenith angles of the Sun in the sky. Its fundamental principle is as follows: the above Eq. (2) is linearized by applying a natural logarithm:

$\ln \left(S_{\lambda}\right)=\ln \left(S_{0, \lambda}\right)-\mu_{\mathrm{w}} \tau_{\lambda}$.

There is one equation available for every single measurement of the direct solar radiation, while $\mu_{\mathrm{w}}$ and $\ln \left(S_{\lambda}\right)$ are the known variables and $\ln \left(S_{0, \lambda}\right)$ and $\tau_{\lambda}$ are the unknown ones. A number of equations equal to the number of measurements will be acquired by applying multiple measurements at various zenith angles of the Sun. Theoretically, it is feasible to determine the unknowns already from two measurements, but for the ETC determination, it is advisable to acquire as many measurements as possible. That will guarantee a higher accuracy of the result. It is essential to linearly interpolate the obtained dependence of natural logarithm of the solar radiation flow density $\ln \left(S_{\lambda}\right)$ on the total air-mass factor of the atmosphere $\mu_{\mathrm{w}}$ using the method of least squares. The slope $a$ of the obtained line (from the equation of a straight line $y=a x+b$ ) equals $\tau_{\lambda}$. The natural logarithm of the ETC $\ln \left(S_{0, \lambda}\right)$ is obtained when $x$ (in the equation of a straight line) equals $0\left(x\right.$ represents $\left.\mu_{\mathrm{w}}\right)$. The ETC for the given wavelength is assumed valid for the entire intercalibration period, hence for 2 years. Its determination follows the following procedure: the ETCs for individual wavelengths can be determined solely from DS measurements that meet the three following conditions:

1. The air-mass factor for the atmosphere as a whole is less than 3 .

2. The AOD calculated as an average of five values within a single DS measurement for the wavelength of $320 \mathrm{~nm}$ is less than 0.5 .

3. The difference between the maximum and minimum value of AOD within a single DS measurement is less than 0.03 .

Additionally, the ETCs are determined only for days that meet the conditions 4 to 9 :
4. The number of direct solar radiation measurements is at least 50 (i.e. 10 DS measurements).

5. The difference between the maximum and minimum air-mass factor for the atmosphere as a whole is greater than 1 .

6. The SD from the measured values of the total ozone on the given day is less than 2.5.

7. The SD from the measured AOD values on the given day is less than 0.07 .

8. $\left|\ln \left(S_{\lambda}\right)_{i}-\ln \left(S_{\lambda}\right)_{j}\right|<1.75 \cdot \frac{\sum_{i, j=1}^{n}\left|\ln \left(S_{\lambda}\right)_{i}-\ln \left(S_{\lambda}\right)_{j}\right|}{n}$, where $\ln \left(S_{\lambda}\right)_{i}$ is the value of $\ln \left(S_{\lambda}\right)$ obtained from the equation of linear interpolation after the substitution of a specific $\mu_{\mathrm{w}}, \ln \left(S_{\lambda}\right)_{j}$ is the actually measured value of $\ln \left(S_{\lambda}\right)$ at the given value of $\mu_{\mathrm{w}}$, and $n$ is the total number of direct solar radiation measurements on the given day. The fundamental principle is to exclude measurements that have too high values of residues of the linear interpolation (greater than or equal to 1.75 times the average of the residues on the given day). The threshold value of 1.75 in the above equation was selected based on the results of an optimization test. The goal of the test was to acquire the maximum possible number of days with very good linear interpolation (the selected days had to meet the ninth condition).

9. The determination coefficient for the linear interpolation is greater than 0.98 .

The conditions defined above were applied respectively. The following criterion was applied to all determined ETCs within the given intercalibration period:

$$
\frac{\mid \text { ETC }- \text { AVERAGE(ETCs) } \mid}{\text { STDEV }(\text { ETCs })}<1.5,
$$

where AVERAGE (ETCs) is the average of the determined ETCs and STDEV (ETCs) is the SD. An average is calculated from the ETCs that meet the said criterion. This average is valid for the entire intercalibration period. The final values of ETCs used to calculate the AOD were available only after two iterations. At the beginning, initial values of AOD were not available. For this reason, it was not possible to apply the second and third criterion and it was also not possible to take into account the effect of aerosols in the calculation of $\mu_{\mathrm{w}}$ and to determine the correction for the diffuse radiation. It was possible to do so on the first and second iteration. The ETC varies around its mean value with regard to the distance of Earth from the Sun. Its correction was carried out according to the recommendation of the Guide to Meteorological Instruments and Methods of Observation (WMO, 2008). The calculation of apparent elevation and apparent zenith angle of the Sun in the sky was also made as per the recommendations of the WMO (WMO, 2008). The apparent elevation of the Sun constitutes the fundamental principle in the calculation of air-mass factor. 


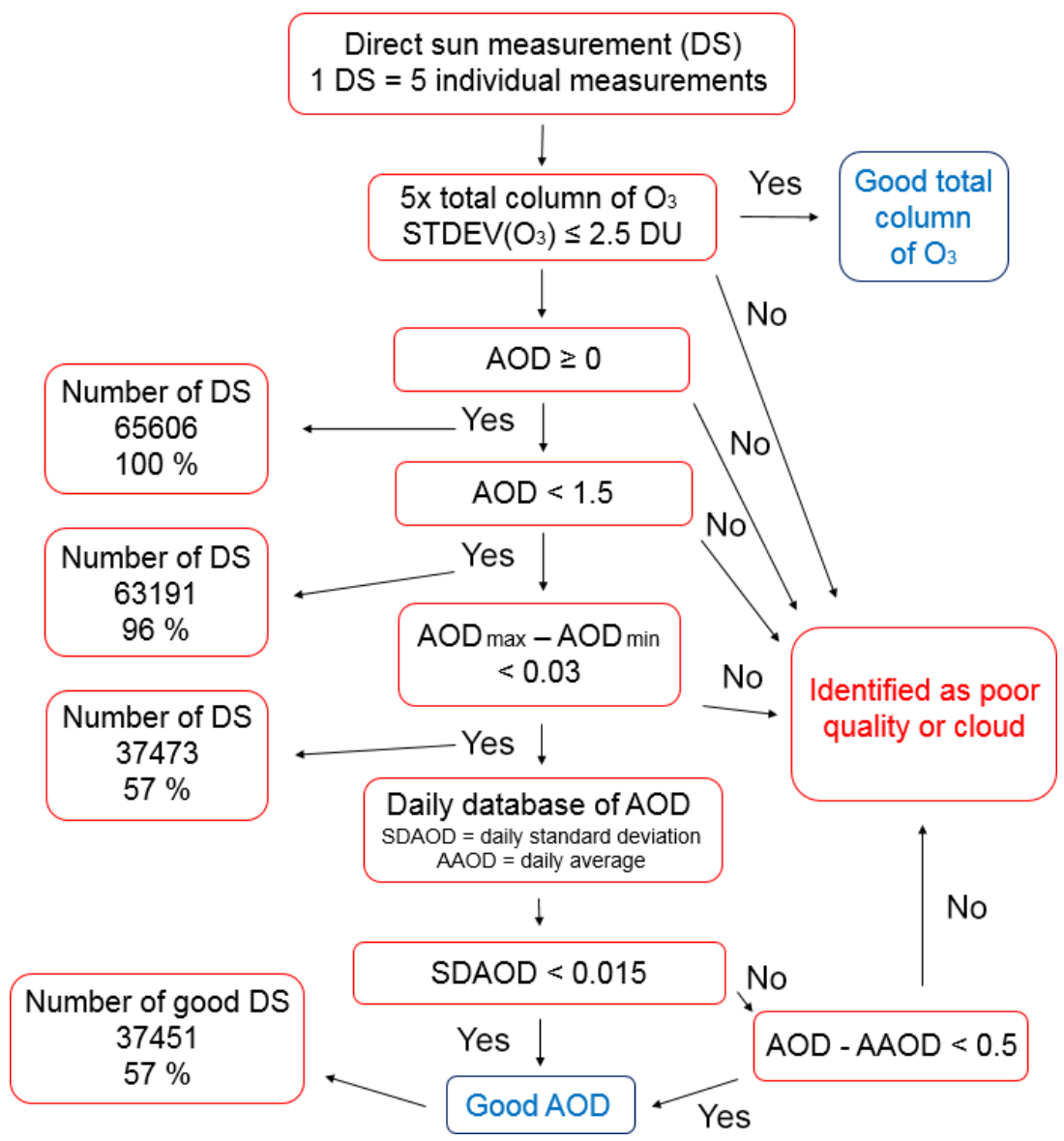

Figure 1. Schematic illustration of the DS measurement quality control procedure that includes cloud screening. The number of DS measurements for the period 18 August 1993-13 May 2017 that satisfy the respective criterion is indicated on the left side.

\subsubsection{Quality control procedure}

All final values of AOD have undergone a quality control procedure, which also includes cloud screening, and is illustrated schematically in Fig. 1. The first step of the quality control was to exclude the DS measurements with a SD for $\mathrm{O}_{3}>2.5 \mathrm{DU}$ (described in more detail in Sect. 2.3). Next, all negative values of AOD were excluded. In the third step, all AOD values $\geq 1.5$ were excluded. Comparison of AOD values above 1.5 obtained from the Brewer spectrophotometer for the Belgian Uccle station determined that they could not be paired with Cimel sun photometer measurements at all (De Bock et al., 2010). It proves that the limit of 1.5 is substantiated for the Poprad-Gánovce station. The fourth step was to exclude the DS measurements with a difference between the maximum and minimum AOD value greater or equal to 0.03 . The international Cimel sun photometer network AERONET uses a limit for each measurement triplet (three measurements per minute) with the value of 0.02 (https://aeronet.gsfc.nasa.gov/new_web/Documents/ Cloud_scr.pdf, last access: May 2018). We decided to apply a less stringent criterion because our case involved five measurements performed in ca. $2.5 \mathrm{~min}$. The attached diagram shows that the limit of 0.03 has caused a considerable reduction in the total number of DS measurements. Application of the second and third criterion has resulted in a reduction of the total number of measurements by up to $43 \%$. The DS measurements that satisfied all four previous criteria were included in a so-called daily database. A daily SD of AOD (SDAOD) and a daily average of AOD (AAOD) were determined from these measurements. When SDAOD $<0.015$, all AOD values in the daily database were transferred to a final database (Good AOD). When SDAOD $\geq 0.015$ in the fifth step, all DS measurements on the given day underwent the sixth and last step. The following applied to the sixth step: when the difference between the AOD for a given DS measurement and the daily average AAOD was $\geq 0.5$, the DS measurement was not included in the final database. A total of 37451 DS measurements were included in the final database. That represents $57 \%$ of the total number of measurements that entered the third step of the quality control. 


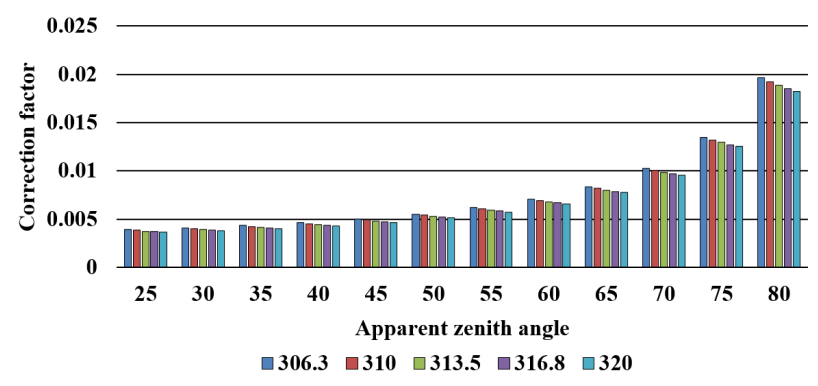

Figure 2. Value of correction factor for the elimination of diffuse radiation impact for the selected zenith angles of the Sun, for five wavelengths for the conditions of AOD with a value of 0.3 (for $320 \mathrm{~nm}$ ) and air pressure of $930 \mathrm{hPa}$.

\subsubsection{Additional notes}

Comparison of AOD values obtained by the Cimel sun photometer with AOD values from the Brewer spectrophotometer was not performed directly. First, the value of the Ångström exponent was determined using pairs of wavelengths and their corresponding AOD values:

$\alpha=-\frac{\log \left(\tau_{\lambda_{1}} / \tau_{\lambda_{2}}\right)}{\log \left(\lambda_{1} / \lambda_{2}\right)}$,

where $\lambda_{1}=340 \mathrm{~nm}$ and $\lambda_{2}=380 \mathrm{~nm}$. On the basis of Ångström exponent and the known value of AOD (for the shorter wavelength), an AOD value for the wavelength of $320 \mathrm{~nm}$ was determined in the next step for the Cimel sun photometer. This calculation was carried out for all individual measurements. The main goal of this calculation was to acquire a comparison of AOD for the same wavelength, which is more relevant than a direct comparison of AOD for two different wavelengths.

The following procedure was employed to calculate individual characteristics of the total ozone and AOD optical depth: daily averages were calculated as an arithmetic average of all values for the given day (minimum of one value). Monthly averages were calculated as an arithmetic average of such days, for which an average daily value was available. Annual averages were calculated as an arithmetic average of individual monthly values. The longest period without data is 12 days for the ozone optical depth and 26 days for AOD. There was no month without data. In both cases, February 2013 was the month with the absolute lowest number of days with the determined optical depth. In the first case, it was 10 days, and it was 3 days in the second case. With regard to the long-term average, December is the month with the lowest number of days with the determined AOD with 13 days. The opposite extreme falls on August with 24 days. A linear trend was calculated by means of a linear regression using the least squares method. An autocorrelation was not confirmed. Therefore, it was possible to determine the linear trend. The uncertainty in the linear trend is defined by the
$\mathrm{SD}( \pm \sigma)$ of the slope of the obtained linear dependence. The value of linear trend and the SD was determined for a period of 10 years. The seasonal cycle was eliminated by annual averages.

\section{Results and discussion}

\subsection{Correction for the diffuse radiation, stray-light effect and polarization}

The results of calculation and application of individual correction factors are presented in the introduction to this part of the paper. A factor that eliminates the influence of diffuse radiation is the first of these factors, as discussed in Sect. 2.4.1. In Fig. 2, there is a demonstration of correction factor values for five wavelengths and the selected sequence of zenith angles of the Sun. This demonstration characterizes the conditions that are close to those that may normally occur at the examined station. It can be seen that this factor is primarily dependent on the zenith angle. It is also true that the value of the factor is inversely proportional to wavelength. The factor for the longest wavelength of $320 \mathrm{~nm}$ is ca. $7 \%$ lower than the factor for the shortest wavelength of $306.3 \mathrm{~nm}$.

Another correction factor was determined to eliminate the stray-light effect, also discussed in Sect. 2.4.1. A ratio of average count rates for four wavelengths in the region from 290 to $291.5 \mathrm{~nm}$ to the count rates for the monitored wavelength (one out of five) was determined for 3386 spectral measurements in total, as well as for various zenith angles of the Sun. The value of the determined correction factor is a function of the zenith angle. This dependence was described for the monitored wavelengths by a polynomial of fourth degree. A demonstration is presented in Fig. 3. As a general rule, lower wavelengths are characterized by higher values of the correction factor. The observed difference between the wavelengths of 306.3 and $320 \mathrm{~nm}$ was approximately 10 fold. Furthermore, it was determined that the dependence on the zenith angle was not directly proportional for all monitored wavelengths. The direct proportion was seen only with the three shortest wavelengths.

The impact of individual correction factors was tested on a shorter period, namely 2014 . When the stray-light effect was accounted for, a drop in the difference in the AOD for the wavelengths of 306.3 and $320 \mathrm{~nm}$ was seen. Before the correction, the difference reached the value of -0.029 , and after the correction, it was decreased by ca. 0.007 . This value is similar to the results in Arola and Koskela (2004). A correction eliminating the polarization of radiation followed after the correction for the stray-light effect. A drop in the difference with the value of 0.008 was observed again. It was then followed by a correction for the impact of diffuse radiation. A drop in the difference was observed again, but it was lower, and its value was only 0.0004 . This result is significantly lower compared to the result presented in Arola and 

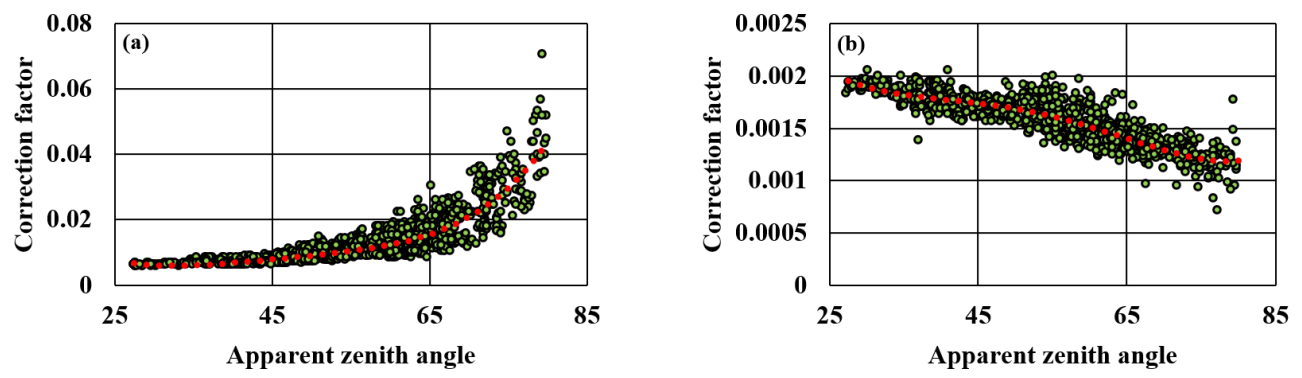

Figure 3. Correction factor for the elimination of the stray-light effect depending on the apparent zenith angle (a) for the wavelength of $306.3 \mathrm{~nm}$; (b) for the wavelength of $320 \mathrm{~nm}$.

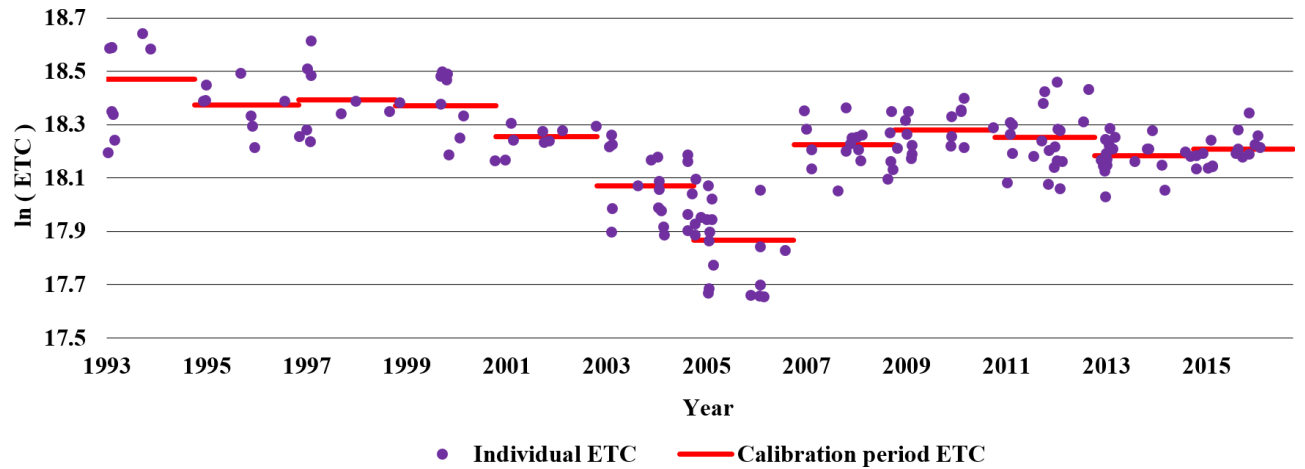

Figure 4. Time series of ETC values for the wavelength of $320 \mathrm{~nm}$ during 12 intercalibration periods, 18 August $1993-13$ May 2017.

Koskela (2004). In conclusion, it can be stated that application of all three corrections resulted in a drop in the difference in AOD for the shortest and the longest wavelength by 0.015 to the final value of -0.014 . The negative value of the Angström exponent for the given pair of wavelengths was reduced, but it still persists.

\subsection{Extraterrestrial constants}

Strict conditions for the selection of appropriate days for the determination of ETCs and other mentioned criteria significantly eliminate non-representative values. To calculate the ETC characterizing the entire 2-year period, 15 values of individual ETCs were employed with respect to the long-term average. If the conditions were less strict, there would have been more days, for which it would be possible to determine the ETC. On the other hand, the spread of determined ETCs would be wider, which would have a negative effect on the required accuracy. Therefore, the chosen criteria represent an optimum compromise. The inaccuracy of ETC determination has a direct impact on the final values of AOD. On one hand, the root cause of such inaccuracy is weather influences, which considerably eliminate the number of days that are suitable for the determination of ETC. On the other hand, additional factors may include instrument instability.

The time series of ETCs (their natural logarithm) for the wavelength of $320 \mathrm{~nm}$ is illustrated in Fig. 4. It shows ETC values that characterize the entire 2-year intercalibration pe- riod, as well as the ETCs determined on individual days in each period. The ETC for the monitored wavelength did not remain constant during the period from 18 August 1993 to 13 May 2017. Particular changes occurred in all five examined wavelengths. A total of 12 ETC values were determined for every single wavelength, 1 for each intercalibration period. The highest instability was observed in the longest wavelength. The value of its variation coefficient is $15.1 \%$. By contrast, the lowest instability was observed for the wavelength of $310 \mathrm{~nm}$. The value of its variation coefficient is $11.6 \%$. In Fig. 4, one can notice that a more significant change in the value of ETC for the longest wavelength occurred three times in total. Changes occurred between the fifth, sixth, seventh and eighth intercalibration period. They were caused by issues with the instrument. For that reason, a secondary power supply board had to be replaced in January 2005. In February 2007, a micrometer was replaced, and during calibration in May 2007, optical filter No. 3 was replaced and a BM-E80 high-frequency source was repaired as well.

Figure 5 presents a comparison of ETC values for individual wavelengths for the LPM and BSM in the last two intercalibration periods. It can be seen that ETC values show some differences. The first period is characterized by the fact that ETCs for all five wavelengths for the LPM exceed the values for the BSM. It is exactly the reverse in the second period. In the case of both methods, there was a decrease in 

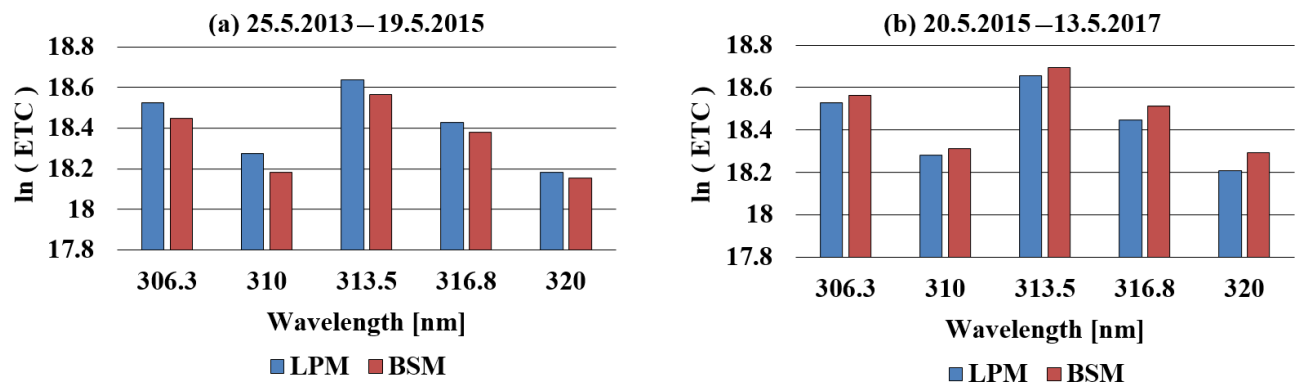

Figure 5. Comparison of ETC values for individual wavelengths for the LPM and BSM.

(a) 25.5.2013-19.5.2015

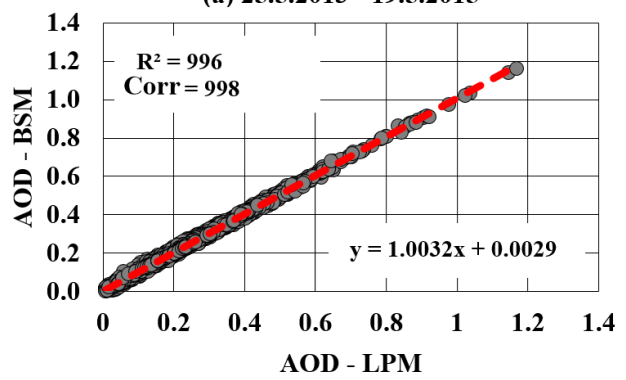

(b) 20.5.2015-31.12.2016

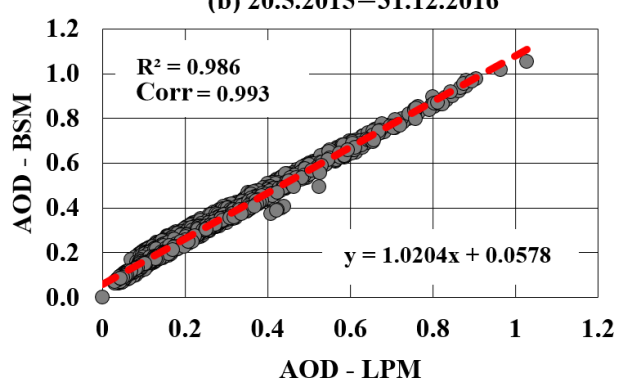

Figure 6. Comparison of AOD values for the wavelength of $320 \mathrm{~nm}$ obtained by means of the LPM and BSM.

ETCs between the given two periods. The decrease for the BSM was more marked.

\subsection{Comparison of AOD values obtained by LPM, BSM and the Cimel sun photometer}

The results for the presented methodology of AOD calculation by means of the LPM was validated in two ways. In the first place, it was confronted with the results acquired by means of the BSM. The given comparison is illustrated in Fig. 6. As has already been mentioned above, the BSM has been available since 2005. Its application has been plausible for the Poprad-Gánovce station only since calibration in 2013. Figure 6 consists of two graphs. Graph (a) represents a comparison of AOD for the wavelength of $320 \mathrm{~nm}$ for the intercalibration period from 25 May 2013 to 19 May 2015. Graph (b) covers the comparison of results for the same wavelength in the next intercalibration period from 20 May 2015 to the end of 2016. This division is necessary to point out the impact of used ETCs on the obtained results. In both intercalibration periods, only the measurements that had undergone the quality control procedure were selected. The absolute difference in AOD between the two methods did not exceed the value of 0.1 in the first period. In the second period, it happened 133 times. The total number of DS measurements in both intercalibration periods was 5788. A total of 3246 DS measurements were compared in the first period and 2542 in the second period. A good agreement of both methods was seen in the first period. On the one hand, it is proven by the very high values of determination and cor- relation coefficients. On the other hand, good agreement is proven by a median and SD $(1 \sigma)$ of the differences in AOD values for the LPM and BSM with the values of -0.004 and 0.01 . The following intercalibration period is also characterized by very high values of determination and correlation coefficients, yet they are somewhat lower than in the first period. A more significant disagreement is proven by the median with the value of -0.06 and the SD with the value of 0.02 . The said differences between the LPM and BSM are not constant within the intercalibration period, as certain variability has been observed for them. The biggest differences within a year are observed in summer months.

Results for the remaining four wavelengths were compared in a similar fashion as well. For the wavelengths of $310,313.5,316.8$ and $320 \mathrm{~nm}$, the value of correlation coefficient reached at least 0.99 . This value was not reached only in case of the lowest wavelength of $306.3 \mathrm{~nm}$ in the first intercalibration period, where it was at the level of 0.97 . The median of differences in AOD between the LPM and BSM reached the maximum absolute value of 0.06 in the already mentioned case for the wavelength of $320 \mathrm{~nm}$. For the lower wavelengths, the median in the first period was always positive ( 0.036 on average). On the contrary, it was always negative in the second period $(-0.03$ on average). The average of SDs for the given four wavelengths was 0.024 in the first period and 0.017 in the second period. Comparison of the AOD value and wavelength shows no unambiguous dependence for neither of the two methods. It applies to the LPM that the highest AOD was reached for the wavelength 

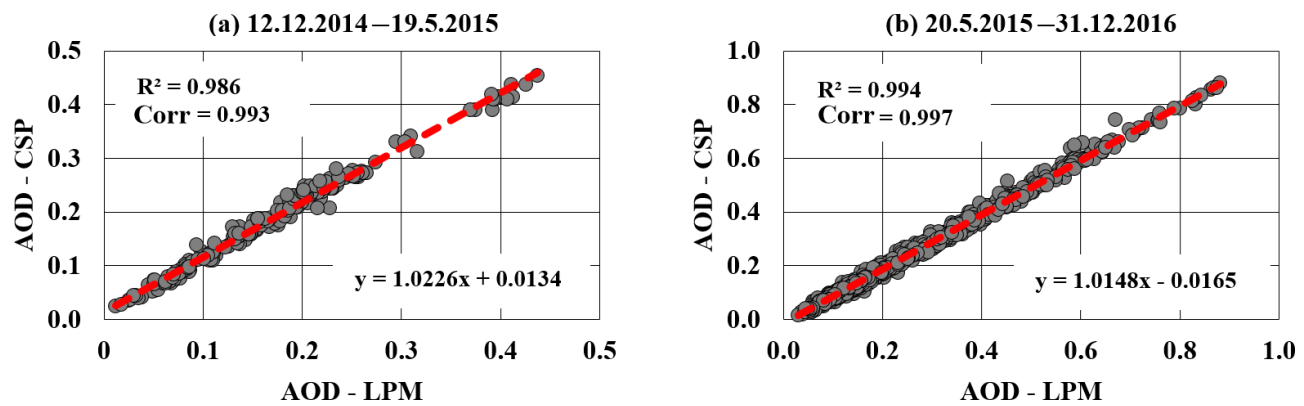

Figure 7. Comparison of AOD values for the wavelength of $320 \mathrm{~nm}$ obtained by means of the LPM and the Cimel sun photometer (CSP).

(a) $12.12 .2014-19.5 .2015$

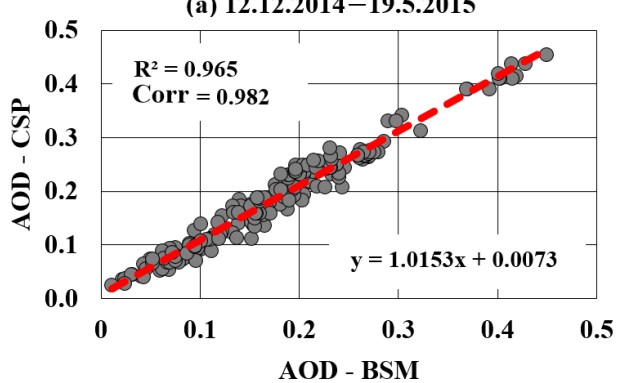

(b) 20.5.2015-31.12.2016

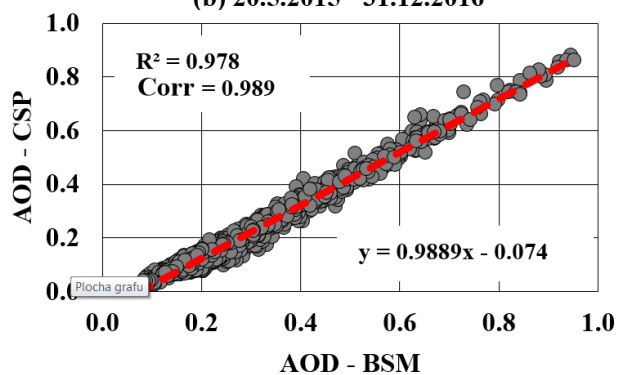

Figure 8. Comparison of AOD values for the wavelength of $320 \mathrm{~nm}$ obtained by means of the BSM and the Cimel sun photometer (CSP).

of $316.8 \mathrm{~nm}$ and the lowest AOD was reached for the wavelength of $320 \mathrm{~nm}$ with regard to the long-term average in the monitored period. It applies to the BSM that the highest AOD was reached for the lowest wavelength of $306.3 \mathrm{~nm}$ and the lowest AOD was reached for the wavelength of $310 \mathrm{~nm}$ with regard to the long-term average. Pribullová (2002) does not mention the unambiguous dependence of AOD on the wavelength as well. It indicates the lowest AOD in case of the lowest wavelength and presents the highest values of AOD for the wavelength of $310 \mathrm{~nm}$.

It follows that the LPM and BSM correlate nicely. On the other hand, observed differences constitute a certain problem. They result in AOD values for the LPM that are lower or higher compared to the AOD values for the BSM. There are several causes for these differences. The first cause is that the BSM does not take into account the annual change in the distance of Earth from the Sun. The presented LPM takes the given change into account. Another difference between the two methods is the fact that the BSM takes into consideration the total measured amount of $\mathrm{SO}_{2}$ in the calculation of AOD. The presented LPM neglects the impact of $\mathrm{SO}_{2}$. It may seem at a glance that the BSM is thus advantaged. However, the reverse is true. The Brewer spectrophotometer at the PopradGánovce station fails to measure the total amount of $\mathrm{SO}_{2}$ accurately. Even negative values are seen often. A disadvantage of BSM is that it does not account for the standard lamp test that leads to inaccurate TCO values, which consequently affects the size of AOD. Another drawback of the BSM is the fact that it does not take into consideration corrections for the diffuse radiation, polarization and stray-light effect. The values of the determined ETCs affect the observed differences the most. However, this is true only when the difference between LPM and BSM is sufficiently large. These constants are fixed for both methods during the entire 2-year intercalibration period. An advantage of the presented LPM is that it partially takes into account the potential change in the sensitivity of the instrument during the intercalibration period, because ETCs are determined based on real measurements in a given period. The BSM utilizes ETCs determined during calibration. Therefore, the potential change in the sensitivity of the instrument during the intercalibration period is not taken into account at all.

Both presented methods were further compared with Cimel sun photometer (CSP) measurements. These comparisons are illustrated in Fig. 7 (for the LPM) and Fig. 8 (for the BSM). The figures consist of two graphs just like in the previous case. In both intercalibration periods, only the DS measurements that had undergone the quality control procedure were selected. The comparison was made as follows: a CSP measurement was selected for an individual DS measurement from the Brewer spectrophotometer with the maximum allowed difference of $5 \mathrm{~min}$ between the two measurements. If there were several suitable measurements, the nearest one was selected. In the case of comparison between the LPM and the CSP, there was no difference in AOD with the absolute value greater than 0.1 . On the contrary, in the case of comparison between the BSM and the CSP, there were as much as 221 instances of such DS measurements in to- 


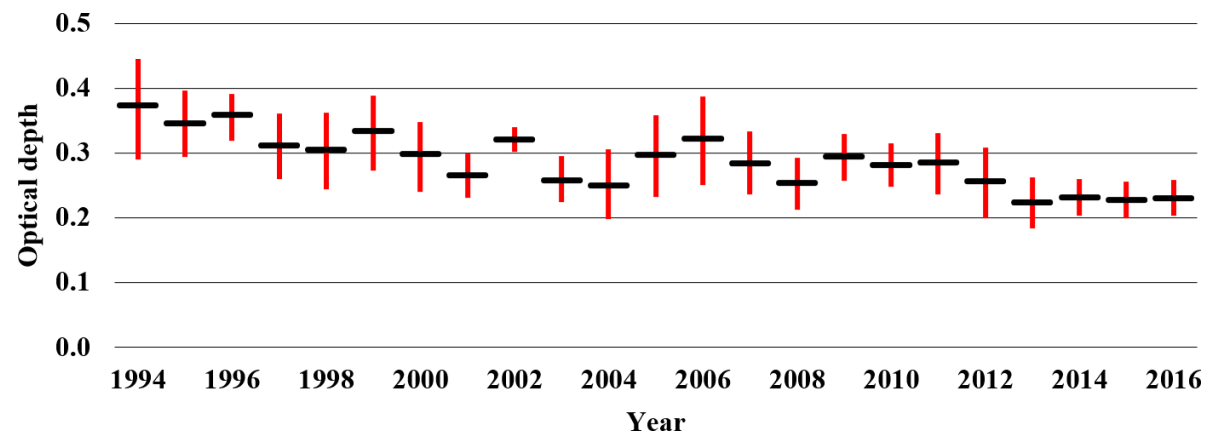

Figure 9. Annual averages of AOD and their uncertainty for the wavelength of $320 \mathrm{~nm}, 1994-2016$.

tal. A total of 199 measurements were compared in the first intercalibration period and 1115 in the second period.

It is apparent from the results of the comparison that both methods correlate very well with the CSP measurements. Yet the LPM shows higher values of the correlation coefficient in both intercalibration periods than the BSM. It was determined in the calculation of differences that both methods matched the CSP measurements well in the first intercalibration period. The median of differences between LPM and CSP was -0.016 , and the median of differences between BSM and CSP was -0.009 . The SD was 0.011 and 0.018 , respectively. In the following period, a good match was observed only for LPM. The median of differences between the LPM and the CSP reached the value of 0.013, and the median of differences between BSM and CSP reached the value of 0.075 . In this case, the SD was 0.013 and 0.025 , respectively. The mentioned differences are the primary reason for observed offsets in attached graphs. As a result of the offset, the intersection of the linear fit is not the same as the intersection of the main axes of the graph. It is best illustrated by graph (b) in Fig. 8, because in this case the median of differences has the highest absolute value of all presented comparisons. In the light of the results, it can be stated that the LPM is the more reliable of the two methods.

\subsection{Total ozone optical depth and AOD}

Measurements of total ozone from the Brewer spectrophotometer for the Poprad-Gánovce station are available from 1994. If only DS measurements are taken into consideration, the average value of total ozone was 326 DU in the last 5 years (2012-2016), which is only 1 DU more than in the first 5 years of the monitored period (1994-1998). The linear trend for the period of 1994-2016 has the value of $0.8 \pm 2.2 \mathrm{DU}$ for 10 years. For that reason, the rising trend of total ozone optical depth for the monitored wavelengths in the period of 1994-2016 was equally statistically insignificant. For the wavelength of $306.3 \mathrm{~nm}$, the value of the trend is $0.005 \pm 0.009$ for 10 years, and the value of the trend for the wavelength of $320 \mathrm{~nm}$ is $0.001 \pm 0.002$ for 10 years.
Figure 9 shows annual averages of AOD for the wavelength of $320 \mathrm{~nm}$ together with the uncertainty in their determination. The annual averages of AOD were calculated in a standard manner, i.e. by means of the LPM method using an average ETC value for every 2-year period shown in Fig. 4. The lower limit of uncertainty was calculated by means of an average value of ETC, from which its SD for the given intercalibration period was deducted. The upper limit of uncertainty was determined in the same way but adding the value of the SD. The range of uncertainty interval depends primarily on weather conditions in the given intercalibration period, as well as on the stability and homogeneity of measurements on days when it was possible to determine the ETC. The number of days, when it was possible to determine the ETC, plays its role too. With regard to the long-term average, the number of these days was 15 . The lowest number within a calibration period was 7 and the highest number was 24.

Figure 10 shows a comparison of annual averages for the total ozone and aerosol optical depth for the selected wavelengths. It is obvious already at a glance that the AOD, unlike the total ozone optical depth, exhibits an apparent decline for the monitored period. For the wavelength of $306.3 \mathrm{~nm}$, the value of the trend is $-0.06 \pm 0.01$ for 10 years, and the value of the trend for the wavelength of $320 \mathrm{~nm}$ is $-0.05 \pm 0.01$ for 10 years. In view of the above, a conclusion can be made that the transmittance of the atmosphere in the region of examined wavelengths has increased in the area of PopradGánovce over the last 23 or 21 years. The total optical depth of the atmosphere for the wavelength of $306.3 \mathrm{~nm}$ has a trend with the value of $-0.06 \pm 0.01$ for 10 years, and its trend for the wavelength of $320 \mathrm{~nm}$ has the value of $-0.05 \pm 0.01$ for 10 years. The negative trend has been caused exclusively by the decline in the AOD.

Figure 11 presents a comparison of multiannual averages for the ozone optical depth, optical depth of Rayleigh scattering and AOD for all five examined wavelengths. It can be seen that ozone is dominant only in case of the shortest wavelength. It is exactly the reverse for the pair of the longest wavelengths, and ozone has the lowest impact among the examined factors. Rayleigh scattering has a dominant position 


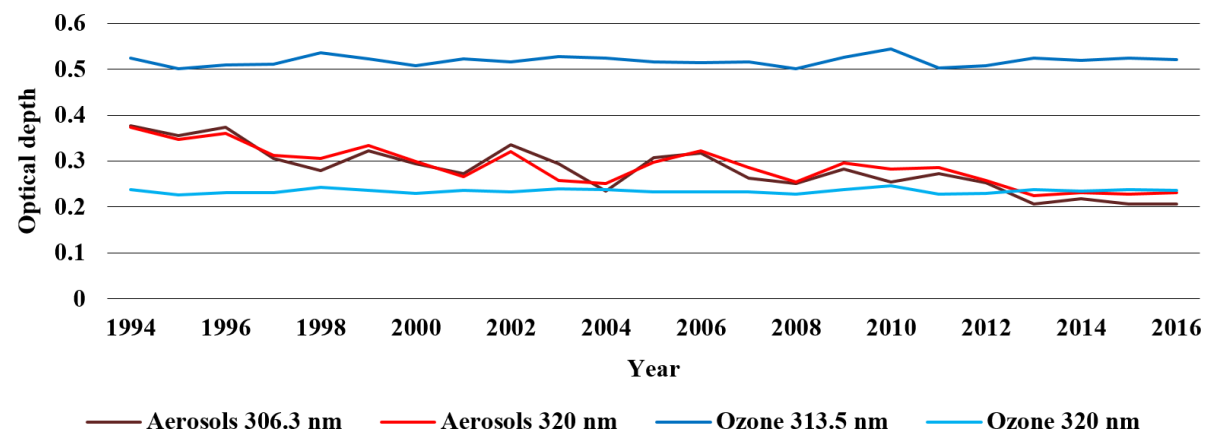

Figure 10. Comparison of values of average annual optical depth for the selected wavelengths for ozone and aerosols, $1994-2016$.

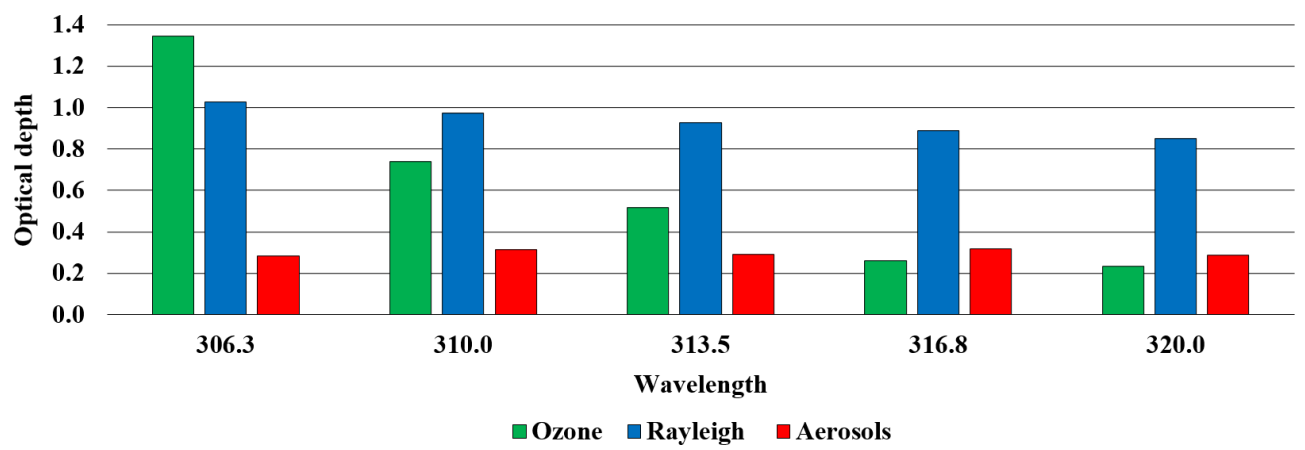

Figure 11. Comparison of long-term averages for the total ozone optical depth, the optical depth of Rayleigh scattering and AOD, 1994-2016.

in attenuation of direct solar radiation for all wavelengths except for the shortest one. In the case of the AOD, no unambiguous dependence on the wavelength was observed. With respect to the long-term average, the AOD reached the highest value for the wavelengths of 310 and $316.8 \mathrm{~nm}$, namely 0.32 . On the contrary, the AOD reached the lowest value for the wavelength of $306.3 \mathrm{~nm}$, namely 0.28 . The wavelengths of 313.5 and $320 \mathrm{~nm}$ are characterized by the value of 0.29 . With regard to the long-term average for 23 years, the difference in AOD between the shortest and the longest wavelengths is only -0.006 . For the test year of 2014, this difference was -0.014 . In conclusion, it can be stated that values of ETC have probably the greatest impact on the observed difference, while the observed difference in AOD is consequently arising from them. This is also substantiated by Fig. 10. It can be seen that the AOD is greater for the wavelength of $306.3 \mathrm{~nm}$ than for the wavelength of $320 \mathrm{~nm}$ in certain years, while it is the reverse in other years.

Figure 12 illustrates an annual cycle of total ozone optical depth and its variability for individual months for the wavelength of $320 \mathrm{~nm}$. The optical depth reaches its maximum in April with the value of 0.263 and the minimum in October with the value of 0.203 . The highest variability is attributed to the month of February and the lowest one to the month of July. It applies to all the months of the year that the variability is considerably lower compared to the average. The month of February has the maximum variation coefficient amount- ing to $5.9 \%$. All the aforementioned characteristics of the total ozone optical depth depend only on the TCO value. It is due to the central European location of the station that the annual maximum of the TCO occurs in April and the annual minimum occurs in October. This is also confirmed by the measurements from the nearby station in Hradec Králové (Vaníček et al., 2012). Therefore, it can be stated that the observed annual course of the total ozone optical depth is typical for the central European location of the station.

Figure 13 is the same as Fig. 12, but ir refers to the AOD in this case. The annual cycle of monthly averages is characterized by two peaks. The primary peak, that is the annual maximum, occurs in the month of August with the value of 0.4. The secondary peak occurs in the month of April with a slightly lower value. The minimum is in the month of December with the value of 0.16 . The variability is also characterized by a two-peak annual cycle. The primary and secondary peaks are in the same months as in the case of the average. The annual minimum occurs in the month of November. The variation coefficient reached significantly higher values compared to ozone. The minimum is attributed to the month of May amounting to $17.1 \%$. The maximum is attributed to the month of December amounting to $42.4 \%$. The location of the station at a higher altitude in the submontane area has the primary impact on the said characteristics, which explains lower values of AOD in winter months. Higher values of AOD in the months of April to September are pre- 


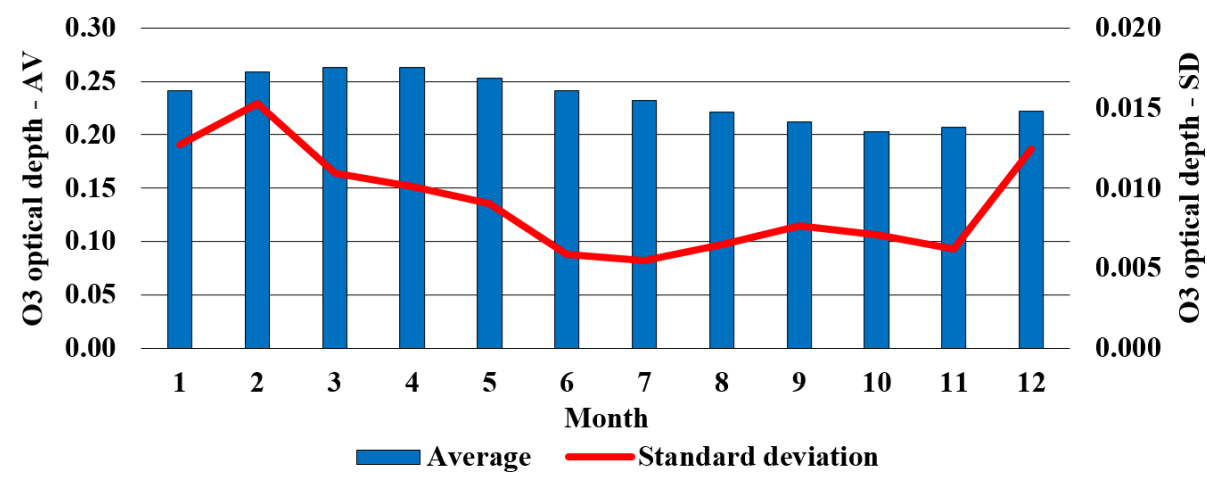

Figure 12. Average monthly characteristics of the total ozone optical depth for the wavelength of $320 \mathrm{~nm}, 1994-2016$.

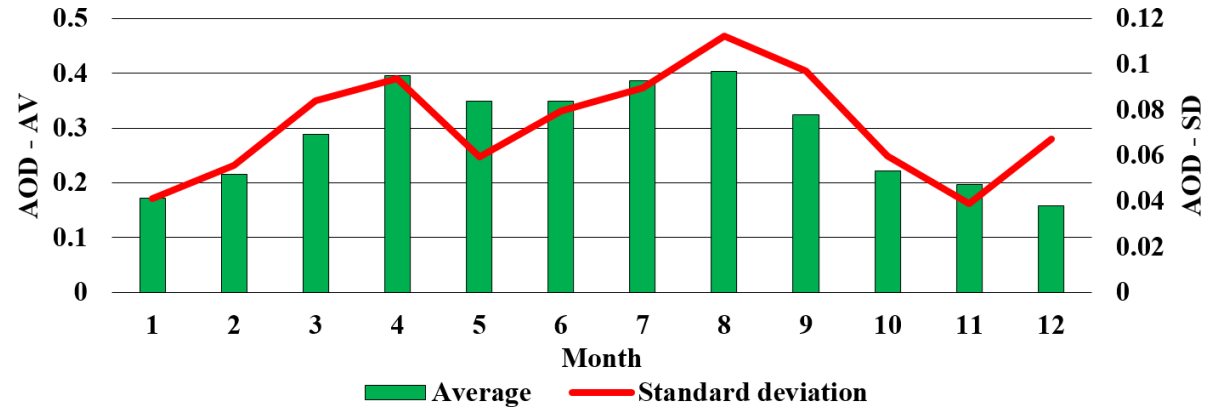

Figure 13. Average monthly characteristics of the AOD for the wavelength of $320 \mathrm{~nm}, 1994-2016$.

sumably related to agricultural activities in the vicinity of the station. The location is windy and bare dry soil or even plant products are often blown away.

Figure 14 shows the relative distribution of daily AOD averages for individual months for the monitored period of 1994-2016. It is important to point out that only the days for which it was possible to determine the AOD were taken into consideration. In the month of December, there is the highest percentage of days with AOD within the interval from 0 to 0.1 , specifically up to $41 \%$. On the contrary, the lowest percentage was seen in the month of June with the value of only $1 \%$. Days with a daily average of AOD above 0.3 dominate in the months of April to August. Days with a daily average of AOD within an interval below 0.3 dominate in the remaining months of the year. The AOD above 0.6 occurs the most often in the month of August, that is in $18 \%$ of days. The lowest percentage of such days is in the month of November and December, namely only $1 \%$. In conclusion, it can be stated that the presented percentages of individual days correlate very well with the annual cycle of AOD in Fig. 13.

\section{Conclusions}

The total ozone and aerosol optical depth were determined by the Brewer ozone spectrophotometer in Gánovce near Poprad. The AOD was calculated by means of ETCs obtained using the Langley plot method (LMP). The analysed data of the direct solar radiation were available from 1994 to 2016, which is a 23-year series of measurements. In the 1990s, the ETCs were not determined during calibrations. Therefore, the LPM is the only practical method for the determination of AOD for the whole series of measurements. The ETCs used in this paper were determined for each of the 2-year intercalibration periods. Use of such a long time period has both an advantage and a disadvantage. The advantage lies in the fact that the ETC determined as an average of a higher number of days prevents the accidental impact of fluctuations that have no particular explanation. The disadvantage lies in the suppression of weather influences (especially the change of temperate) and modifications of the instrument in time intervals of less than 2 years. In addition to the methodology of ETC determination, the employed cloud screening affects the values of AOD as well. If cloud screening was not employed, the values of AOD would have been distinctly higher. The cloud screening method employed in this paper is relatively simple. Hence, it can be argued that the actual AOD is even somewhat lower. It pertains particularly to the presented monthly and annual averages. In the future, the cloud screening methodology is planned to be improved. As a result, it will be possible to obtain more representative values of AOD.

On the basis of a comparison of the Brewer spectrophotometer measurements using the LPM and the BSM, which is a part of the Brewer operating software, with Cimel sun 


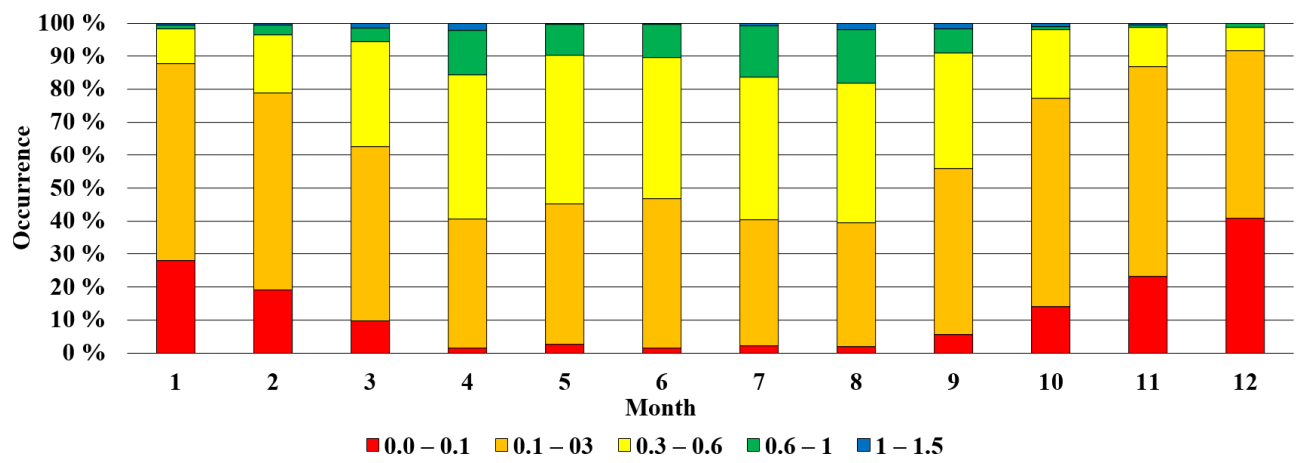

Figure 14. Relative contribution of daily average values of AOD to the monthly averages for the wavelength of 320 nm, $1994-2016$.

photometer measurements, it was determined that the LPM achieved better results. It was also determined that the application of corrections to the diffuse radiation, stray-light effect and polarization decreased the difference between the value of AOD for the shortest and longest of the examined wavelengths. Although the difference has been reduced, it still reaches negative values, which results in the negative values of the Angström exponent as well. With regard to the long-term average for 23 years, the difference in AOD is only -0.006 . The application of the correction for the polarization had the most significant influence on the reduction of the given difference. On the contrary, the lowest contribution was achieved by the correction with regard to the diffuse radiation. The key factor influencing the value of the examined difference is probably the size and accuracy of ETC determination.

The obtained results clearly show the decrease in average annual values of the total optical depth of the atmosphere for the monitored wavelengths from 1994 to 2016. A statistically insignificant slightly upward trend of the total ozone has been observed, which is exhibited by a statistically insignificant increase in the total ozone optical depth. This insignificant increase has only a minimal effect on the trend of the total optical depth of the atmosphere. The root cause of the decrease in the total optical depth of the atmosphere is the statistically significant decline in the AOD. It follows that the transmittance of the atmosphere in the UV region of the spectrum from 306.3 to $320.1 \mathrm{~nm}$ has increased in the location of Poprad-Gánovce.

Data availability. The data used in the research and presented in this paper are available from the author upon agreement. It is recommended to send a request by email.

Competing interests. The author declares that he has no competing interests.
Special issue statement. This article is part of the special issue "Quadrennial Ozone Symposium 2016 - Status and trends of atmospheric ozone (ACP/AMT inter-journal SI)". It is a result of the Quadrennial Ozone Symposium 2016, Edinburgh, United Kingdom, 4-9 September 2016.

Acknowledgements. The author of the paper thanks the Slovak Hydrometeorological Institute for the provision of data. A special acknowledgement goes to Anna Pribullová for running the station of the Aerological and Radiation Centre, SHMI, in Poprad-Gánovce. The author also thanks the Faculty of Mathematics, Physics and Informatics of the Comenius University in Bratislava for the possibility of external PhD study in meteorology and climatology, during which this paper was prepared. Many thanks also to the organizing team of international the Quadrennial Ozone Symposium held in Edinburgh on 4-9 September 2016, namely, inter alia, for the provision of financial support. Finally, the author thanks the European Aerosols, Clouds, and Trace gases Research Infrastructure (ACTRIS) for providing the calibration of the Cimel sun photometer

The ACTRIS-2 project has received funding from the European Union's Horizon 2020 research and innovation programme under grant agreement no. 654109 .

Edited by: Alkiviadis Bais

Reviewed by: two anonymous referees

\section{References}

Alpert, P., Shvainshtein, O., and Kishcha, P.: AOD trends over megacities based on space monitoring using MODIS and MISR, Am. J. Clim. Change, 12, 117-131, https://doi.org/10.4236/ajcc.2012.13010, 2012.

Arola, A. and Koskela, T.: On the sources of bias in aerosol optical depth retrieval in the UV range, J. Geophys. Res., 109, D08209, https://doi.org/10.1029/2003JD004375, 2004.

Bass, A. M. and Paur, R. J.: The ultraviolet cross-sections of ozone. I. The measurements, II. Results and temperature dependence, in: Atmospheric ozone, Proceedings of the Quadrennial ozone symposium, 3-7 September 1984, Halkidiki, Greece, 606-616, 1985. 
Bodhaine, B. A., Wood, N. B., Dutton, E. G., and Slusser, J. R.: On Rayleigh Optical Depth Calculations, J. Atmos. Ocean. Tech., 16, 1854-1861, 1999.

Brewer, A.: A replacement for the Dobson spectrophotometer?, Pure Appl. Geophys., 106, 919-927, 1973.

Carlund, T., Kouremeti, N., Kazadzis, S., and Gröbner, J.: Aerosol optical depth determination in the UV using a four-channel precision filter radiometer, Atmos. Meas. Tech., 10, 905-923, https://doi.org/10.5194/amt-10-905-2017, 2017.

Carvalho, F. and Henriques, D.: Use of Brewer ozone spectrophotometer for aerosol optical depth measurements on ultraviolet region, Adv. Space Res., 25, 997-1006, 2000.

Cede, A., Kazadzis, S., Kowalewski, M., Bais, A., Kouremeti, N., Blumthaler, M., and Herman, J.: Correction of direct irradiance measurements of Brewer spectrophotometers due to the effect of internal polarization, Geophys. Res. Lett., 33, L02806, https://doi.org/10.1029/2005GL024860, 2006.

Cheymol, A. and De Backer, H.: Retrieval of the aerosol optical depth in the UV-B at Uccle from Brewer ozone measurements over a long time period 1984-2002, J. Geophys. Res., 108, 4800, https://doi.org/10.1029/2003JD003758, 2003.

Cheymol, A., De Backer, H., Josefsson, W., and Stubi, R.: Comparison and validation of the aerosol optical depth obtained with the Langley plot method in the UV-B from Brewer Ozone Spectrophotometer measurements, J. Geophys. Res., 111, D16202, https://doi.org/10.1029/2006JD007131, 2006.

Cimel Electronique: CE318 Photometer User's Operation Manual, Cimel Electronique, Paris, France, 2015.

Czerwińska, A. E., Krzyścin, J. W., Jarosławski, J., and Posyniak, M.: Effects of urban agglomeration on surface-UV doses: a comparison of Brewer measurements in Warsaw and Belsk, Poland, for the period 2013-2015, Atmos. Chem. Phys., 16, 13641-13651, https://doi.org/10.5194/acp-16-13641-2016, 2016.

De Bock, V., De Backer, H., Mangold, A., and Delcloo, A.: Aerosol Optical Depth measurements at $340 \mathrm{~nm}$ with a Brewer spectrophotometer and comparison with Cimel sunphotometer observations at Uccle, Belgium, Atmos. Meas. Tech., 3, 1577-1588, https://doi.org/10.5194/amt-3-1577-2010, 2010.

De Bock, V., De Backer, H., Van Malderen, R., Mangold, A., and Delcloo, A.: Relations between erythemal UV dose, global solar radiation, total ozone column and aerosol optical depth at Uccle, Belgium, Atmos. Chem. Phys., 14, 12251-12270, https://doi.org/10.5194/acp-14-12251-2014, 2014.

de Meij, A., Pozzer, A., and Lelieveld, J.: Trend analysis in aerosol optical depths and pollutant emission estimates between 2000 and 2009, Atmos. Environ., 51, 75-85, https://doi.org/10.1016/j.atmosenv.2012.01.059, 2012.

Finlayson-Pitts, B. J. and Pitts, J. N.: Chemistry of the upper and lower atmosphere: theory, experiments, and applications, Academic Press, San Diego, USA, 2000.

Garane, K., Bais, A. F., Kazadzis, S., Kazantzidis, A., and Meleti, C.: Monitoring of UV spectral irradiance at Thessaloniki (19902005): data re-evaluation and quality control, Ann. Geophys., 24, 3215-3228, https://doi.org/10.5194/angeo-24-3215-2006, 2006.

Gorshelev, V., Serdyuchenko, A., Weber, M., Chehade, W., and Burrows, J. P.: High spectral resolution ozone absorption crosssections - Part 1: Measurements, data analysis and comparison with previous measurements around $293 \mathrm{~K}$, Atmos. Meas. Tech., 7, 609-624, https://doi.org/10.5194/amt-7-609-2014, 2014.

Greinert, R., de Vries, E., Erdmann, F., Espina, C., Auvinen, A., Kesminiene, A., and Schuz, J.: European Code against Cancer, 4th edition: Ultraviolet radiation and cancer, Cancer Epidem. Biomar., 39, S75-S83, 2015.

Hrabčák, P.: Saharan dust over Slovakia, Meteorol. J., 19, 83-91, 2016.

IPCC: Climate Change 2013: The Physical Science Basis. Contribution of Working Group I to the Fifth Assessment Report of the Intergovernmental Panel on Climate Change, edited by: Stocker, T. F., Qin, D., Plattner, G.-K., Tignor, M., Allen, S. K., Boschung, J., Nauels, A., Xia, Y., Bex, V., and Midgley, P. M., Cambridge University Press, Cambridge, United Kingdom and New York, NY, USA, 1535 pp., https://doi.org/10.1017/CBO9781107415324, 2013.

Jansen, M. A., Gaba, V., and Greenberg, B. M.: Higher plants and UV-B radiation: balancing damage, repair and acclimation, Trends Plant Sci., 3, 131-135, 1998.

Jarosławski, J., Krzysćin, J. W., Puchalski, S., and Sobolewski, P.: On the optical thickness in the UV range: Analysis of the groundbased data taken at Belsk, Poland, J. Geophys. Res., 108, 4722, https://doi.org/10.1029/2003JD003571, 2003.

Kasten, F.: A new table and approximation formula for the relative optical air mass, Arch. Meteor. Geophy. B, 14, 206-223, 1966.

Kasten, F. and Young, A. T.: Revised optical air mass tables and approximation formula, Appl. Optics, 28, 4735-4738, 1989.

Kazadzis, S., Bais, A., Amiridis, V., Balis, D., Meleti, C., Kouremeti, N., Zerefos, C. S., Rapsomanikis, S., Petrakakis, M., Kelesis, A., Tzoumaka, P., and Kelektsoglou, K.: Nine years of UV aerosol optical depth measurements at Thessaloniki, Greece, Atmos. Chem. Phys., 7, 2091-2101, https://doi.org/10.5194/acp7-2091-2007, 2007.

Kerr, J. B.: The Brewer Spectrophotometer, in: UV Radiation in Global Climate Change, edited by: Gao, W., Slusser, J. R., and Schmoldt, D. L., Springer, Berlin, Heidelberg, 2010.

Kimlin, M. G. and Schallhorn, K. A.: Estimations of the human "vitamin D" UV exposure in the USA, Photochem. Photobio. S., 3, 1067-1070, 2004.

Kirchhoff, V. W. J. H., Silva, A. A., Costa, C. A., Lem, N. P., Pavao, H. G., and Zaratti, F.: UV-B optical thickness observations of the atmosphere, J. Geophys. Res., 106, 2963-2973, 2001.

Komhyr, W.: Operations Handbook - Ozone Observations with a Dobson Spectrophotometer, WMO Global Ozone Research and Monitoring Project, Report No. 6, WMO Geneva, 1980.

Krotkov, N. A., Bhartia, P. K., Herman, J. R., Fioletov, V., and Kerr, J.: Satellite estimation of spectral surface UV irradiance in the presence of tropospheric aerosols 1 . Cloud-free case, J. Geophys. Res., 103, 8779-8793, 1998.

Kumharn, W., Rimmer, J. S., Smedley, A. R. D., Ying, Y. T., and Webb, A. R.: Aerosol Optical Depth and the Global Brewer Network: A Study Using UK- and Malaysia-Based Brewer Spectrophotometers, J. Atmos. Ocean. Tech., 29, 857-866, 2012.

Liu, S. C., McKeen, S. A., and Madronich, S.: Effect of anthropogenic aerosols on biologically active ultraviolet radiation, Geophys. Res. Lett., 18, 2265-2268, 1991.

Lyamani, H., Olmo, F. J., and Alados-Arboledas, L.: Physical and optical properties of aerosols over an urban location in Spain: 
seasonal and diurnal variability, Atmos. Chem. Phys., 10, 239254, https://doi.org/10.5194/acp-10-239-2010, 2010.

Marenco, F.: On Langley plots in the presence of a systematic diurnal aerosol cycle centered at noon: A comment on recently proposed methodologies, J. Geophys. Res., 112, D06205, https://doi.org/10.1029/2006JD007248, 2007.

Marenco, F., di Sarra, A., and Di Luisi, J.: Methodology for determining aerosol optical depth from Brewer 300$320 \mathrm{~nm}$ ozone measurements, Appl. Optics, 41, 1805-1814, https://doi.org/10.1364/AO.41.001805, 2002.

Mishchenko, M. I. and Geogdzhayev, I. V.: Satellite remote sensing reveals regional tropospheric aerosol trends, Opt. Express, 15, 7423-7438, https://doi.org/10.364/OE.15.007423, 2007.

Nieke, J., Pflug, B., and Zimmermann, G.: An aureolecorrected Langley-plot method developed for the calibration of HiRES grating spectrometers, J. Atmos. Sol.-Terr. Phy., 61, 739-744, 1999.

Pribullová, A.: Spectral UV aerosol optical thickness determinated from the Poprad-Gánovce Brewer spectrophotometer observations, Contrib. Geophys. Geodesy., 32, 291-307, 2002.

Raghavendra Kumar, K., Narasimhulu, K., Balakrishnaiah, G., Suresh Kumar Reddy, B., Rama Gopal, K., Reddy, R. R., Satheesh, S. K., Krishna Moorthy, K., and Suresh Babu, S.: A study on the variations of optical and physical properties of aerosols over a tropical semiarid station during grassland fire, Atmos. Res., 95, 77-87, https://doi.org/10.1016/j.atmosres.2009.08.012, 2010.

Redondas, A., Evans, R., Stuebi, R., Köhler, U., and Weber, M.: Evaluation of the use of five laboratory-determined ozone absorption cross sections in Brewer and Dobson retrieval algorithms, Atmos. Chem. Phys., 14, 1635-1648, https://doi.org/10.5194/acp-14-1635-2014, 2014.

Serdyuchenko, A., Gorshelev, V., Weber, M., Chehade, W., and Burrows, J. P.: High spectral resolution ozone absorption crosssections - Part 2: Temperature dependence, Atmos. Meas. Tech., 7, 625-636, https://doi.org/10.5194/amt-7-625-2014, 2014.

Savastiouk, V.: Improvements to the direct-sun ozone observations taken with the Brewer spectrophotometer, PhD Thesis, York University, Toronto, Kanada, 2006.
Savastiouk, V. and McElroy, C.: Brewer spectrophotometer total ozone measurements made during the 1998 Middle Atmosphere Nitrogen Trend Assessment (MANTRA) campaign, Atmos. Ocean, 43, 315-324, 2005.

Schwartz, S. E. and Warneck, P.: Units for use in atmospheric chemistry, Pure Appl. Chem., 67, 1377-1406, 1995.

SCI-TEC Instruments Inc.: Brewer MKIV Spectrophotometer Operator's Manual, SCI-TEC Instruments Inc., Saskatoon, Canada, 1999.

Seinfeld, J. H. and Pandis, S. N.: Atmospheric chemistry and physics: From air pollution to climate change, 2nd edition, John Wiley \& Sons, Inc., New Jersey, USA, 2006.

Sellitto, P., di Sarra, A., and Siani, A. M.: An improved algorithm for the determination of aerosol optical depth in the ultraviolet spectral range from Brewer spectrophotometer observations, J. Opt. A, 10, 849-855, 2006.

Silva, A. A. and Kirchhoff, V. W. J. H.: Aerosol optical thickness from Brewer spectrophotometers and an investigation into the stray-light effect, Appl. Optics, 43, 2484-2489, 2004.

Vaníček, K., Metelka, L., Skřivánková, P., and Stanek, M.: Longterm changes of the ozone layer over the Czech republic, 1st edition, Transaction of the Czech Hydrometeorological Institute, Vol. 56, Published by the Czech Hydrometeorological Institute, Praha, Czech republic, 68 pp., 2012.

WHO: Air quality guidelines: global update 2005: particulate matter, ozone, nitrogen dioxide, and sulfur dioxide, Tech. rep., World Health Organization, Geneva, Switzerland, 2006.

WMO: Guide to meteorological instruments and methods of observation, World Meteorological Organization, WMO - No 8, 7th Edn., Geneva, Switzerland, 2008.

WMO: Scientific Assessment of Ozone Depletion: 2014, World Meteorological Organization, Global Ozone Research and Monitoring Project-Report No. 55, Geneva, Switzerland, 2014.

Zerefos, C. S., Tourpali, K., Eleftheratos, K., Kazadzis, S., Meleti, C., Feister, U., Koskela, T., and Heikkilä, A.: Evidence of a possible turning point in solar UV-B over Canada, Europe and Japan, Atmos. Chem. Phys., 12, 2469-2477, https://doi.org/10.5194/acp-12-2469-2012, 2012. 